\section{4e WHY WE NEED VISION ZERO: THE UPS AND DOWNS OF CONSTRUCTION SAFETY IN THE USA}

Knut Ringen. CPWR - The Centre for Construction Research and Training, Seattle, USA

\subsection{6/oemed-2018-ICOHabstracts.244}

Between 1990 and 2010, the USA experienced a decline in construction fatality rates of about $40 \%$. By then, as a result of the Great Economic Recession, the industry had lost $25 \%$ of all workers and employers. By 2014 the industry was gaining back some of that employment, and suddenly we saw a large increase in fatality rates. By 2015, this increase had wiped out all the gains made between 2000 and 2010. This was not a surprise. In fact, based on past experience, CPWR predicted this would happened when the recession struck. Today there is full employment, and there is a shortage of both contractors and workers. To fill this void, new employers and new workers, with little experience, enter the industry and pose tremendous risks. How can such shortsightedness be mitigated? First, stronger regulations are needed. The requirements to get a business license as a construction contractor are minimal. In most states, there are no requirements for workers to have minimal skills or safety training before they get a job.

While the regulatory approach is essential -the backbone of any safety system - it is also minimal. It is not possible to regulate excellence. Excellence comes from culture, not requirements.

We know this, because there are sectors of construction within the US, and construction companies, that achieve such excellence. But we can also show that conditions can easily be created that foster risk taking.

That's why Vision Zero is so important. It provides the core of a safety culture that is easy to grasp. CPWR has created its version of Vision Zero, and has developed two implementation tools. The first is the Safety Climate self-assessment tool known as S-CAT, which allows any construction organisation or work site to assess its performance over eight broad indicators. It is now available online, and free of charge. The second is a training program called Foundations for Safety Leadership.

Excellence in safety can be achieved, but it requires commitment from everyone. That's what is captured in Vision Zero.

\section{Dermatology and Radiation}

\section{TITLE OF (JOINT) SPECIAL SESSION 'OED' AND 'RADIATION AT WORK': HOW TO TACKLE THE INCREASING DISEASE BURDEN OF OCCUPATIONAL SKIN CANCER}

${ }^{1}$ Swen Malte John, ${ }^{2}$ Fabriziomaria Gobba. 'Dept. Dermatology, Environmental Medicine, Health Theory, University of Osnabrueck, Germany; ${ }^{2}$ University of Modena \& Reggio Emilia, Modena, Italy

\subsection{6/oemed-2018-ICOHabstracts.245}

Aim of special session Obtain better knowledge of epidemiological and clinical aspects, SR exposure mechanisms and biological interactions to raise awareness and implement preventive strategies

Solar Radiation (SR) is associated to various skin cancers: actinic keratosis (AK), squamous cell carcinoma (SCC) basal cell carcinoma (BCC), and malignant melanoma (MM). Occupational activity is one of the most relevant factors influencing SR exposure. Alone in Europe about 14.5 million outdoor workers (OW) are exposed to SR for at least $75 \%$ of their working time. The prevalence of occupational skin cancer among OW is very high and increasing. Most countries do not recognize skin cancer as an occupational disease.

\section{6a MAIN FACTORS INFLUENCING OCCUPATIONAL SOLAR UV EXPOSURE}

Fabriziomaria Gobba. University of Modena \& Reggio Emilia, Modena, Italy

10.1136/oemed-2018-ICOHabstracts.246

Several factors of various type can influence solar UV exposure of Outdoor Workers (OWs). A significant part of the solar UV is absorbed by stratospheric ozone layer, so the reduction of the ozone layer, that is currently ongoing, is progressively increasing the amount of UV reaching the earth surface and, consequently, the worker's exposure.

Among other, main relevance have geographical factors and first of all the latitude and also the altitude. Furthermore, as UV exposure varies with the elevation angle of the Sun above the horizon, exposure depends on the season and month of the year and hour of the day, being maximal between 11 a.m. and 3 p.m. about. Meteorological factors as clouds have an obvious relevance, but a variable proportion of UV, up to the $90 \%$, can penetrate light clouds. Atmospheric composition/pollution has a variable effect, as suspended particles can absorb or reflect/refract/diffuse UV rays.

Different working factors can significantly interfere with UV exposure in OWs, as the surfaces surrounding the area of work: e.g. fresh snow or metals, especially if polished, reflects a high proportion of UV, while green grass absorbs up to the 98-99\%. Working postures can significantly modify the exposure of different parts of the body during outdoor activities. Other occupational factors include the presence of UV shelters, like roofing or vegetation. The organization of task is also important: e.g. activities avoiding direct exposure during the central hours of the day, and work breaks, as meals, in UV protected environments are highly effective to reduce exposure. Other important working factors are the use of sunglasses with adequate UV filtering lenses, brimmed hats, UV absorbing cloths and a correct use of sunscreens $S P F \geq 30$. A last individual factor that cannot be ignored is the role of personal protective behaviours of the worker, as habits to seek the sun.

\section{$1616 \mathrm{~b}$ QUESTIONNAIRE BASED EVALUATION OF THE WHOLE- LIFE HISTORY OF SOLAR UV RADIATION EXPOSURE IN A GROUP OF PATIENTS IN ITALY}

Alberto Modenese. University of Modena \& Reggio Emilia, Modena, Italy

10.1136/oemed-2018-ICOHabstracts.247

Introduction An adequate evaluation of the ultraviolet (UV) cumulative exposure is a major problem in epidemiological studies on chronic skin damage. Questionnaires may be applied as useful tools. For these reasons, a detailed questionnaire for the evaluation of individual cumulative exposure to Solar Radiation (SR) of outdoor workers (OWs) was 